of this attitude of the British Medical Association and of the local practitioners as a body and of the warning notice of the medical journals the medical staff of the hospital held a meeting at which it was unanimously decided that the whole staff resign.

In conclusion, I would again emphasise the facts (1) that the staff of the Hampstead General Hospital resigned on a matter of principle; (2) that we took this step in deference to the wishes of the British Medical Association and of the local practitioners of the neighbourhood; (3) that after being associated so long with this institution, having been present at its birth, having watched its evolution and growth with increasing pleasure and pride, and having guided it into its present state of maturity, we have not resigned our posts on the staff lightly.

Lastly, is it too much to express the hope that the leaders of the profession will stand shoulder-to-shoulder with the general practitioners in this struggle, and will demonstrate once more, as was done at Bristol, that we are all brethren? I am, Sir, yours faithfully,

Augustus $\mathrm{H}$. Cook,

Senior Surgeon, Hampstead General Hospital.

Hampstead, Feb. 24th, 1908.

\section{RECEPTION HOUSES FOR RECENT CASES OF INSANITY.}

\section{To the Editor of The LANCET.}

SIR,-I am sorry your correspondent, "A Medical Superintendent, County Asylum (England)," writes anonymously, as in general I do not care to reply to such communications. There are some points, however, raised by your correspondent which show that he has not grasped the substance of my communication. This may be due to a want of lucidity on my part, but the contention of my paper was that it is quite possible to treat all classes of recent admissions to asylums under exactly similar conditions to those that prevail in general hospitals, without seclusion and restraint. I was not aware that about 90 per cent. of the English asylums have carried out the methods suggested in my paper, but my error is excusable in view of the fact that several medical superintendents of English county asylums, members of the London County Council, and other English county councils, who have visited the reception house at Woodilee, were not conversant with any similar mode of dealing with recent admissions. Perhaps your correspondent will emerge from his anonymity and give the name of some of the places where he knows the system spoken of is in vogue.

In regard to your correspondent's remarks about the doors being locked at night, I may say in this connexion that there would be no objection to the doors being unlocked at night so far as the nursing and the care of the patients are concerned, but doors are locked on the same principle on which the medical superintendent of a county asylum locks the doors of his own house at night.

I sympathise with the attitude of your correspondent with regard to female nurses being in charge of the male hospital. I had the same views as he now holds, previous to the introduction of such nursing into this institution, and after a short trial of female nurses I thought my primary views were to be confirmed. A subsequent and more efficient trial has convinced me of the value of female nurses in the hospital for male patients. Is there something so radically different in mental disease as to demand a different system of nursing to that of general bodily disease? There are no male nurses, as far as I know, in general hospitals.

Your correspondent's reference to the recovery-rate at Woodilee Asylum is not a happy one. During the seven years I have been superintendent of this institution there has been an average recovery-rate of 37 per cent. on the admissions. This average, as far as I am aware, does not fall far below the usual. I assume that your correspondent's reason for bringing forward the recovery-rate is that in view of the conditions under which newly admitted patients are treated there ought to be a larger recovery-rate. Perhaps your correspondent is not aware of local conditions which influence the recovery-rate of this institution. In Glasgow we have mental wards in which temporary cases of insanity (which swell recoveryrates), such as cases of delirium tremens and doubtful cases of illness, are treated to a conclusion. Secondly, we have in this asylum a home for imbecile children, and there has been during recent years a comparatively large number of children admitted annually who, as they are all included in the admission numbers, adversely affect the recovery-rate. If there is any other point that your correspondent would like information on I will be very glad to afford it him.

I am, sir, yours faithfully,

HAMILTON C. MARR.

Glasgow District Asylum, Woodilee, Feb. 25th, 1908.

\section{AN ÆSTHESIA AND ITS MORTALITY. To the Editor of THE LANCET.}

SIR,-I am asked by "G. H. R. D." to explain a statement which I made at the last meeting of the Medico-Legal Society. It is quite true that I there pleaded for a more thorough instruction in the administration of anæsthetics as a prelude to a reduction in the present regrettably high death-rate from these agents. So far as I am able to follow his arguments, "G. H. R. D." contends that if my thesis is correct we should expect to find a lower death-rate at those hospitals at which instruction is most thorongh. Up to this point I fully agree with him-in fact, it would not, I think, be difficult to prove this contention. But when he states that the mortality from ansesthetics is lower in provincial, Scotch, and Irish hospitals than in our London hospitals I confess I cannot follow him. I am sure there are other readers of THE LANCET besides myself who would be glad to know how he has arrived at the data upon which be has based this statement. I take it he is aware that there are no coroners' inquests in Scotland-a fact which has for many years stood in the way of any comparison between the respective anæsthetic death-rates of England and Scotland. But even if "G. H. R. D." were able to bring forward statistics in support of his statement I very much question whether such statistics would satisfy the profession, for there is, perhaps, no question before us at the present time concerning which statistics are more likely to be fallacious than that under consideration. It seems to me that if deaths during anæsthesia are to be reduced in number-and I maintain that such an achievement is perfectly practicable-this can only be done by increasing and disseminating the knowledge we already possess of the clinical and physiological action of these substances; by placing their administration at our hospitals in the hands of experienced and specially appointed officers; and by exerting all the means in our power to prevent inexperienced and unqualified persons, outside our hospitals, from employing drugs with whose properties they are not sufficiently familiar.-I am, Sir, yours faithfully,

Frederic Hewitt.

\section{To the Editor of THE LANCET.}

SrR,-As I am to some extent responsible for the teaching of anæsthetics in the Edinburgh Medical School and for the methods employed by those who give the anrsthetics, I may be permitted to, so far as may be, reply to "G. H. R. D.'s", query in your issue of Feb. Z2nd. As to the use of a towel Dr. D. is under a misapprehension-or his informant is. The use of the towel for the administration of chloroform in an Edinburgh hospital is now unusual. Schimmelbusch's mask is most commonly employed for pure $\mathrm{CHCl}_{3}$, with one or two layers of lint. I prefer two myself. For mixtures$\mathrm{C}$ E. and $\mathrm{C}_{1} \mathrm{E}_{2}-\mathrm{a}$ metal cone (modified from Black's) is frequently employed. In many theatres Clover or Hewitt is used from time to time for ether, frequently preceded by ethyl chloride, while latterly the open method of etherisation has got a foothold, and my colleague Dr. D. O. A. McAlium, I believe, frequently employs it. The methods and anæsthetics employed are therefore varied; probably chloroform is given most frequently. In private practice the cnstom varies with the seniority and conservatism of the individual doctor.

From knowledge I can say that of late years the mortality in hospitals in Edinburgh has been very low and comparatively few cases have come under notice in private practice, owing, I think, largely to the disrepute into which chloroform has fallen in dental work. As to why the mortality is so low in Edinburgh just now and why it is so amazingly high in some hospitals and districts of the metropolis it is impossible to venture an opinion even. The figures given by Mr. Troutbeck at a recent meeting of the Medico-Legal Society are startling.

We cannot claim for one moment that anæsthetic teaching is more carefully or systematically carried out in Scotland than in London or that anything more than care and 